ISSN 1981-416X

Licenciado sob uma Licença Creative Commons

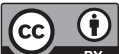

\title{
Inclusão digital e práticas de leitura em um telecentro de uma comunidade quilombola
}

\section{Digital inclusion and reading practices in a telecentro \\ Inclusión digital y prácticas de lectura en un telecentro de una comunidad quilombola}

\author{
Maria Jacy Maia Velloso ${ }^{[a]}$, Maria Lúcia Castanheira ${ }^{[b]^{*}}$ \\ [a] Universidade Estadual de Montes Claros (Unimontes), Montes Claros, MG, Brasil \\ [b] Universidade Federal de Minas Gerais (UFMG), Belo Horizonte, MG, Brasil
}

\section{Resumo}

No contexto de implementação de políticas públicas de inclusão digital no território brasileiro, o artigo analisa as práticas de leitura associadas ao uso do computador e da internet em um telecentro de uma comunidade quilombola, Paineiras, situada ao norte de Minas Gerais, Brasil. Foram adotadas a abordagem do Letramento como Prática Social e uma perspectiva etnográfica para a análise de como e porquê os usuários do telecentro utilizam o computador e a internet e que ações e interações desenvolvem com o estabelecimento desse telecentro na comunidade. A análise dos eventos de leitura observados no telecentro tornou visível duas modalidades de uso dos computadores, que foram classificadas como modalidade de uso livre e modalidade de uso orientado. O contraste entre essas modalidades evidenciou que as práticas de leitura na primeira modalidade estavam mais

\footnotetext{
*MJMV: Doutora em Educação, e-mail: m.jacy@hotmail.com
}

MLC: Doutorado em Educação, e-mail: lalucia@gmail.com 
diretamente vinculadas a interesses pessoais e funções sociais da escrita no contexto digital, particularmente a comunicação com amigos e parentes em redes sociais. Em contraposição, as práticas de leitura desenvolvidas de maneira orientada durante o curso de informática oferecido aos moradores de Paineiras, apresentaram natureza descontextualizada e sem vínculos com as experiências e necessidades vivenciadas pelos alunos em outros espaços sociais, privilegiando o ensino das funções dos softwares (e.g. Excel, Word). Evidenciou-se que as reivindicações, as necessidades, os conhecimentos e os interesses da população não têm sido consideradas no processo de desenvolvimento de cursos de inclusão digital, o que desmotiva os alunos a participarem das atividades propostas e limita as possibilidades de aprendizagem por parte deles.

Palavras-chave: Inclusão digital. Letramentos. Telecentro.

\section{Abstract}

In the context of the implementation of public policies for digital inclusion in Brazil, this article examines reading practices associated with computer and internet use by residents of Paineiras, a quilombola community located in the north of the state of Minas Gerais, Brazil. A Literacy as Social Practice approach and an ethnographic perspective were explored to examine how and why people use computers and the internet and what actions and interactions they developed with the establishment of a telecentre in this community. The analysis made visible two modalities of use of computers, which were classified as free use and oriented use. The contrast between these modalities showed that reading practices in the first modality were more directly related to personal interests and social functions of writing, particularly, communication with friends and relatives in social networks. In contrast, the reading practices developed in the second modality, associated with a digital course offered to residents of Paineiras, showed no links to students' experiences, interests, and needs, privileging the teaching of software (e.g. Excel). The analysis presented suggests that the digital course's decontextualized approach discouraged students to engage with the proposed teaching activities and limited their learning possibilities of digital resources.

Keywords: Digital inclusion. Literacies. Telecentro. 


\section{Resumen}

En el contexto de implementación de políticas de inclusión digital en el territorio brasileño, el artículo analiza las prácticas de lectura asociadas al uso del ordenador y de la internet desarrolladas por usuarios de un telecentro de la comunidad quilombola Paineiras ubicada al norte de Minas Gerais, Brasil. El abordaje teórico adoptado fue de la literacidad como práctica social y una perspectiva etnográfica para el análisis de cómo y por qué los usuarios del telecentro utilizan el ordenador y la internet, y, además, qué acciones e interacciones desarrollan con la implantación del telecentro en la comunidad. El análisis de los eventos de lectura desarrollados por los participantes del grupo observado hizo visible dos modalidades de uso de los ordenadores que fueron clasificados como uso libre y uso orientado. El contraste entre estas modalidades evidenció que las prácticas de lectura en la primera modalidad (libre) estaban más directamente vinculadas a intereses personales y funciones sociales de la escritura en el contexto digital, particularmente, la comunicación con amigos y parientes en redes sociales. En contraposición, las prácticas de lectura desarrolladas de manera orientada durante el curso de informática ofrecido a los habitantes de Paineiras presentaron naturaleza descontextualizada y sin vínculos con las experiencias y necesidades de los alumnos desarrolladas en otros espacios sociales, privilegiando la enseñanza de las funciones de los softwares (e.g. Excel, Word). EI análisis presentado sugiere que las reivindicaciones, las necesidades, los conocimientos y los intereses de la población no se han considerado en el proceso de desarrollo de cursos de inclusión digital, lo que desmotiva a los alumnos y limita sus posibilidades de aprendizaje.

Palabras clave: Inclusión digital. Literacidades. Telecentro.

\section{Introdução}

No contexto de implementação das políticas de inclusão digital no território brasileiro, o artigo analisa as práticas de leitura no uso do computador e da internet desenvolvidas por usuários de um telecentro de uma comunidade quilombola situada ao norte de Minas Gerais/ Brasil. No Brasil, ao longo das últimas décadas, consolidaram-se diversas 
formas de implementação de políticas públicas para inclusão digital; dentre elas, a criação e manutenção de espaços denominados telecentros, que são espaços públicos e comunitários sem fins lucrativos, com vistas à democratização de acesso à internet e que possibilitam a construção de projetos coletivos de uso da tecnologia pela comunidade atendida (MICTIC ${ }^{1}$, 2018). Segundo Zenha e Cordeiro (2012), as iniciativas de implantação de telecentros reivindicavam a consolidação de uma cultura digital a partir do reconhecimento do direito dos indivíduos ao acesso à informática e à internet, compartilhamento de informações, software livre e participação da sociedade no mundo virtual.

Em 2009, o governo federal lançou o Programa Nacional de Apoio a Inclusão Digital nas Comunidades - Telecentros - BR, instituído pelo decreto $n^{\circ} 6.991$, de 27 de outubro de 2009, tendo como eixo central o apoio à inclusão digital nas comunidades através da manutenção, implementação e ações nos telecentros em todo território brasileiro. De acordo com os documentos oficiais, o objetivo principal desse formato era o de promover o desenvolvimento social e econômico das comunidades atendidas, reduzindo a exclusão social e criando oportunidades para os cidadãos (BRASIL, 2010).

Vários telecentros foram instalados em várias regiões do Brasil (atualmente existem mais de 7.755 telecentros, segundo dados do Ministério do Planejamento, Desenvolvimento e Gestão²). Entretanto, pouco foi investigado sobre as práticas educacionais desenvolvidas nesses espaços ou sobre como os recursos tecnológicos dos telecentros são explorados pelo público alvo. Neste texto, buscamos contribuir para o preenchimento dessa lacuna por meio da análise de práticas de leitura (BATISTA, 2014) desenvolvidas por usuários do telecentro Maria Rocha da comunidade de Paineiras ${ }^{3}$, formada por remanescentes das comunida-

${ }^{1}$ Cf. <http://www.mctic.gov.br/mctic/opencms/comunicacao/SETEL/inclusao_digital/telecentros/ TELECENTROS.html>.

${ }^{2}$ Cf. <https://www.governodigital.gov.br/cidadania/inclusao-digital/telecentros>.

${ }^{3}$ Utilizamos pseudônimos para lugares e pessoas. 
des de quilombos ${ }^{4}$, localizada no norte do estado de Minas Gerais, Brasil. Essa temática será examinada por meio da análise de eventos de letramento (HEATH, 1983; STREET, 1984; 2003; STREET e CASTANHEIRA, 2014) que foram identificados durante o desenvolvimento de uma pesquisa de abordagem etnográfica sobre as práticas de letramento no contexto digital (VELLOSO, 2015). Examinaremos questões da seguinte natureza: Como usuários do telecentro Maria Rocha, alunos de um curso de inclusão digital exploram o computador e a internet? Que práticas de leitura foram desenvolvidas pelos usuários do centro ao utilizarem computadores? Antes de passarmos ao exame dessas questões, revisitaremos algumas proposições acerca da leitura como prática social exploradas como aporte teórico neste estudo.

\section{Desenvolvimento}

O letramento é um campo de pesquisa que contribui para a reflexão sobre as possibilidades de usos sociais da leitura e escrita em contextos sociais diferenciados, incluindo contextos digitais, e sobre como usos locais da escrita estão relacionados a movimentos globais ou contextos distantes. Desde o advento dos Novos Estudos do Letramento (NEL) tem sido reconhecida uma pluralidade de práticas culturais de leitura e de escrita, cuja compreensão só é possível ao se considerar o contexto particular em que se desenvolvem. Street (1984), um dos expoentes do NEL, a partir de pesquisa desenvolvida em uma comunidade rural no Irã, estabeleceu a distinção entre dois modelos culturais do letramento, a saber: o modelo autônomo e o modelo ideológico. A partir do modelo autônomo do letramento, a leitura e a escrita são consideradas como independentes do contexto social em que são desenvolvidas e, portanto, desvinculadas

\footnotetext{
${ }^{4}$ Segundo a Cartilha Direitos dos Povos e Comunidades Tradicionais (2013) consideram-se remanescentes das comunidades dos quilombos os grupos étnico-raciais, segundo critérios de autoatribuição, com trajetória histórica própria, dotados de relações territoriais específicas, com presunção de ancestralidade negra relacionada com a resistência à opressão histórica sofrida.
} 
de fatores econômicos, políticos e históricos que possam determinar seus usos e suas consequências para indivíduos e grupos sociais. Ademais, a partir dessa perspectiva, do domínio da escrita, entendida como uma tecnologia neutra, decorreria, de maneira inequívoca, o desenvolvimento cognitivo individual e avanço econômico dos povos de forma universal.

Ao examinar evidências de que tais pressupostos não poderiam ser sustentados e a natureza ideológica desses argumentos, Street (1984) articulou o que denomina de modelo ideológico do letramento, a partir do qual entende-se o letramento como prática social e reconhece-se que seus usos e consequências estão enraizados em visões de mundo particulares a que se vinculam usos, funções e significados sociais da escrita. Assim, em contraposição ao modelo autônomo, o modelo ideológico reconhece a natureza social do letramento, privilegiando a análise de aspectos culturais, políticos, econômicos e relações de poder. Conforme argumenta Street, "as formas como as pessoas se apropriam da leitura e da escrita estão endereçadas e enraizadas nas concepções de conhecimento, identidade e ser" (STREET, 2003, p. 78).

Entendemos que a exploração do modelo do "letramento ideológico" (STREET, 2003, 2014), ou seja, compreender o letramento como um fenômeno de natureza social e política, contribuiu para o exame e a interpretação de diferentes dimensões de práticas de letramento. Estas, desenvolvidas por diferentes grupos e em diferentes espaços sociais, inclusive a leitura e a escrita associadas aos usos das novas tecnologias de comunicação. Dessa forma, entende-se que também o letramento digital está relacionado a "[...] uma variedade de práticas sociais e concepções de engajamento na elaboração de significados. Tal processo se dá mediado por textos que são produzidos, recebidos, distribuídos e compartilhados" (LANKSHEAR; KNOBEL, 2006. p. 17). Neste sentido, acreditamos que a utilização da tecnologia não é neutra, mas uma prática social (LANKSHEAR; SNYDER; GREEN, 2000; STREET, 1984). Assim, a partir da compreensão do letramento como uma prática social, buscamos uma maneira de examinar as variações nos usos e significados da leitura no contexto digital. 
A expressão "práticas de letramento" refere-se tanto a práticas de leitura como de escrita. Como neste texto privilegiaremos a análise de eventos e práticas de leitura no contexto digital, teceremos algumas considerações teóricas que orientaram a construção e interpretação dos dados. Segundo Street e Castanheira (2014), eventos de letramento e práticas de letramento são conceitos estreitamente relacionados: eventos de letramento são situações sociais observáveis mediadas por atividades que envolvem a leitura e a escrita, enquanto que o conceito de práticas de letramento "distancia-se do contexto imediato em que os eventos ocorrem, para situá-los e interpretá-los em contextos institucionais e culturais a partir dos quais os participantes atribuem significado à escrita e à leitura, e aos eventos de que participam" ( STREET, CASTANHEIRA, 2014, p. 40). Dessa forma, a estruturação dos conceitos de eventos e de práticas de letramento está associada à descrição dos modos como o letramento acontece em situações específicas.

Nessa mesma perspectiva, Bloome (1992), ao considerar a natureza dialógica da leitura, afirma que o modo como as pessoas envolvem-se com a leitura e os significados sociais que a atribuem está relacionado às atividades culturais das quais participam. A leitura faz parte de nossas atividades diárias - comer, trabalhar, brincar, aprender, falar — sendo uma atividade cultural, pois envolve nossas "formas compartilhadas de atuar, valorizar, sentir, crer e pensar" (BLOOME, 1992, p. 66). Como processo social, a leitura, segundo Bloome e Egan-Robertson (1993), é apreendida como uma atividade com a qual as pessoas se orientam em relação às outras, se controlam, adquirem status ou posições sociais, adquirem acesso às recompensas e privilégios sociais e se engajam em vários tipos de interação social. Os contextos sociais de leitura são formados pelo modo como as pessoas interagem umas com as outras e pelo status social que elas atribuem umas às outras. Para examinar tais contextos é preciso indagar quem faz o que (por exemplo, lê), com quem, para que, onde, quando e com que consequências para si e para os outros (BLOOME, 1992). Assim, ao explorarmos tal perspectiva, entendemos que os significados da leitura em meio digital tornam-se visíveis na ação dos usuários, no modo como 
se orientam, como se orientam diante da tela de um computador, como participam das interações sociais no espaço virtual, como lidam com as descontinuidades da leitura na tela e como buscam e produzem significados em suas práticas de leitura.

A compreensão da natureza socialmente situada e dialógica da relação entre leitor e texto no contexto digital, conforme discutido acima, orienta o exame de como se realiza a materialização da leitura no telecentro. Interessa-nos examinar o que e como leem os usuários do telecentro e quais os significados da leitura neste contexto particular, tendo em vista sua articulação a um movimento global de inclusão digital, particularmente esforços desenvolvidos pelo poder público brasileiro na implementação de políticas públicas de inclusão digital, por meio da implantação de telecentros em comunidades rurais.

Os eventos de letramento analisados neste texto integram um banco de dados construído por meio do desenvolvimento de uma pesquisa de abordagem etnográfica (GREEN; BLOOME, 1997; HEATH; STREET, 2008) sobre as práticas de leitura no contexto digital. O banco de dados inclui notas de campo, vídeos e gravações em áudio de entrevistas e interações entre participantes dentro e fora do telecentro, coletados ao longo de dois anos (2013-2014) na comunidade de Paineiras. A comunidade é formada, em sua maioria, por pessoas negras, parentes, descendentes dos primeiros ocupantes da comunidade que viveram há mais de 150 anos nessa terra. O provimento das famílias conjuga a produção agrícola e a criação de animais com a migração sazonal, nos meses de maio a setembro, para a região da cafeicultura no sul de Minas Gerais.

O telecentro foi implantado nessa comunidade através de um projeto de extensão do Instituto Federal do Norte de Minas Gerais (IFNMG) Campus Januária/Minas Gerais e contemplado pela Chamada Pública nº 01/2011 do Ministério das Comunicações e da Secretaria Geral da Presidência da República em apoio à capacitação no uso das tecnologias da informação e comunicação para a juventude rural. O telecentro foi inaugurado no dia 9 de março de 2012 para promover a capacitação de jovens entre 14 e 29 anos para o uso do computador e da internet, como 
forma de integração social e potencialização das suas capacidades na agricultura familiar.

O telecentro Maria Rocha dispunha de 15 computadores, dois aparelhos de ar condicionado, 6 mesas de madeira com 3 lugares, 16 cadeiras modelo escritório e um conjunto de mesa e cadeira de escritório que ficava no centro da sala. Os moradores de Paineiras podiam utilizar o telecentro quando estivesse aberto, estando uma das instrutoras no local ou durante as aulas do curso de inclusão digital. Havendo demanda de uso fora dos horários das aulas, os usuários deveriam buscar as chaves com as instrutoras em suas casas. Em dezesseis de março de 2013, a presidente da associação da comunidade de Paineiras explicou que o telecentro ficava fechado a maior parte do tempo e que enfrentavam dificuldades de acesso à chave desse espaço, pois a chave ficava com um membro da comunidade que, às vezes, se recusava a disponibilizá-la. Assim, o horário de funcionamento do telecentro estava frequentemente vinculado ao horário do curso de inclusão digital, que acontecia aos sábados das 14 h00 às 16 h00. Assim, poucas vezes presenciamos o telecentro aberto fora do horário desse curso.

No curso de inclusão digital havia 10 (dez) alunos matriculados; no entanto, a frequência média era de 6 (seis) a 8 (oito) alunos por aula. Esses alunos se encontravam em uma faixa etária entre 14 e 16 anos, todos estudantes de uma escola pública na cidade sede do município e não apresentavam defasagem de idade ou ano de escolaridade. Uma instrutora cursava o 3. ano de graduação do curso de Geografia em uma faculdade particular na cidade de Januária e a outra cursava o ensino médio na cidade sede do município da comunidade de Paineiras.

Durante as observações, as conversas informais e um exame das atividades das quais esses alunos participavam foram sendo levantadas, de forma a organizar as informações relativas ao objeto da investigação, ajudando na focalização das observações em 2 (duas) instrutoras e 4 (quatro) alunas do curso de inclusão digital. Ambas instrutoras foram designadas para serem responsáveis pelo acesso ao espaço do telecentro pela Associação de Remanescentes de Quilombolas de Paineiras (ARQUIP). 
As aulas no telecentro iniciavam-se com a abertura do local por uma das instrutoras, que ligava os computadores, escolhia uma máquina, sentava-se e acessava um site de uma rede social. Os alunos chegavam a pé ou de moto, cumprimentavam os colegas e as instrutoras, sentavam-se à frente de sua máquina, ligavam-na frequentemente sem pedir ajuda das instrutoras, acessavam sites de redes sociais, entre outros. A seguir, a transcrição de um momento inicial da aula quando da escolha do computador:

13h e 47min - Chega uma aluna de motocicleta ao telecentro e entra. (A escolha do computador se dá pelo fato de alguns deles terem acesso à internet e outros não.)

Aluna: Oi Clara, esse pega?(apontando para o computador)

Clara (instrutora): O segundo pega.

A aluna senta-se ao lado de Clara e liga o computador.

Clara e a aluna acessam a rede social.

(Nota de campo 18/05/2013).

A escolha da máquina a ser utilizada através da pergunta "Esse pega?" sinalizou que a falta de manutenção regular nos computadores gerava a inoperância das máquinas. No dia sete de julho de 2013, ao fazer um levantamento sobre as condições de uso das máquinas, detectamos que somente 6 (seis) computadores acessavam a internet, sendo que os computadores restantes apresentavam problemas com vírus, desatualização do software e falta de equipamentos (processador, mouse). Evidentemente, tais limitações, associadas às dificuldades de acesso ao espaço físico do telecentro, reduziam ainda mais as oportunidades de uso do maquinário pelos moradores da comunidade e, consequentemente, as possibilidades de inclusão digital.

A seguir examinaremos as seguintes questões: Quais práticas de leitura eram desenvolvidas pelos usuários do telecentro Maria Rocha? O que leram? Como leram? Com que finalidade? Para responder a essas perguntas, selecionamos eventos de letramento para a construção de diferentes 
ângulos de análises da leitura no contexto digital, possibilitando salientar como as práticas de leitura foram instauradas no telecentro.

Ao realizar uma análise contrastiva dos eventos de letramento observados, notamos que esses eventos estavam vinculados a duas modalidades de uso dos computadores, que foram classificadas como a modalidade de uso livre e a modalidade de uso orientado. Na modalidade de uso livre, o usuário definia por si mesmo o que queria acessar e qual atividade seria realizada no computador. Na modalidade de uso orientado, o usuário devia realizar atividades do curso de inclusão digital, em dias e horários marcados. A seguir, examinaremos eventos e práticas de leitura ocorridas durante o uso dos computadores nessas duas modalidades.

O evento de letramento selecionado como âncora para a análise das práticas de leitura na modalidade de uso livre dos computadores iniciou-se com o acesso à internet por uma aluna para o entretenimento, como redes sociais e sites de busca. Durante esse evento, realizando a leitura realizando movimentos com os lábios e em voz baixa, a aluna acessou a rede social, leu alguns posts e abriu outra janela, acessou o mecanismo de busca, escreveu a palavra "futsal" e acessou um site contendo as regras de duração de uma partida. Voltou para a página principal da rede social, leu alguns posts, voltou para a tela do sistema de mecanismo de busca contendo as opções dadas pelo sistema, passou para a tela das regras do jogo de Futsal, leu algumas informações, clicou em alguns links da página principal do site e voltou para a página principal do Facebook. Em seguida, voltou para a tela que continha algumas regras do jogo, leu e fez anotações no caderno.

Essa aluna comentou em uma conversa sobre o fato de ler em voz baixa para si mesma - "Às vezes eu leio assim... devagar... parece que a gente entende melhor o texto... sei lá... Você fica mais concentrada presta atenção na sua voz e no texto. Eu falo baixinho é pra não atrapalhar os outros...". Segundo ela, a leitura da tela em voz baixa possibilitava a análise com mais atenção das informações disponibilizadas pelo site, indicando que estava falando para si mesma com o intuito de uma melhor compreensão do texto. Notou-se, ainda, que a leitura em voz baixa se fez pelo 
fato de ficar em harmonia com o grupo, seguindo o comportamento social do telecentro, ou seja, evitar perturbar outras pessoas. Como ela, outros usuários também liam em voz baixa as páginas de sites, e, a partir de um link, clicavam em outro, se redirecionando para outro assunto ou outra página, e assim por diante, "navegando" por diversas páginas e muitas vezes voltando à sua página inicial de busca.

A análise de eventos de leitura, quando o computador era utilizado de maneira livre, como o descrito acima, evidenciou ainda que o uso de diferentes telas simultâneas como possibilidade de construção de significados para os textos lidos foi uma ação constante, sempre realizada de forma rápida, seja no movimento de rolagem de barra para visualização do texto verticalmente, seja na alternância das telas.

As análises dessa modalidade livre de uso dos computadores também evidenciaram que o percurso da leitura era realizado de modo variado pelos usuários do centro, posto que cada um deles ia estabelecendo rotas próprias para navegar na internet. A leitura na tela consistia, na maioria do tempo, no reconhecimento visual de ícones e de unidades de significação que o usuário encontra com grande frequência para navegação, como abrir a janela de acesso à internet, ler e se informar sobre os campos onde digitar ou ler resultados de pesquisa. Foi percebido certo domínio por parte dos alunos para leitura na tela e um entendimento das operações de navegação, principalmente para aquelas que levavam à rede social Facebook. Assim, foi possível inferir que os alunos já haviam memorizado rotas de navegação para o acesso ao Facebook, pois esses demonstravam características típicas de um "leitor imersivo" (SANTAELLA, 2004).

Além disso, foi possível evidenciar que a faceta semiótica das imagens e ícones se constituiu por uma heterogeneidade de representações visuais (imagens, fotos, desenhos, emoticons, vídeos) que eram exploradas para a navegação e para produção de sentidos dos textos lidos. Observamos ainda que na modalidade de uso livre dos computadores, os leitores se posicionavam sobre o que liam através do clique, ao curtirem 
e compartilharem postagens, ao responderem a mensagens, ao selecionarem o texto a ser lido.

Argumentamos que as maneiras de ler no espaço do telecentro se apoiaram no sistema social mais amplo, por exemplo, durante as observações, os usuários dos computadores faziam longos períodos de silêncio quando da leitura dos posts, imagens, vídeos e mensagens encontradas na rede social. À primeira vista, pensamos que o silêncio manifestado por todos ao acessar a internet estivesse intimamente relacionado à navegação não linear do ciberespaço por requisitar uma maior atenção do leitor, por sua linguagem hipertextual, em que os alunos têm a oportunidade de navegar em um texto em rede que possibilita uma gama de informações, imagens e sons. No entanto, verificou-se que tal silêncio respondia tanto a uma necessidade do contexto local imediato (não perturbar outras pessoas presentes no telecentro), como ao estabelecimento de relações com contextos distantes por meio do estabelecimento de comunicação com outros participantes do contexto digital. Havia, assim, outros usuários "distantes" envolvidos no processo de interação com os textos lidos, pois, na medida em que se lia, comentava-se algum post na rede social, via-se fotos dos amigos e se estabeleciam relações por meio de elementos da interface denominados "curtir", "comentar", "compartilhar", "post normal", "post com links" que permitem a participação social na rede.

Dessa forma, confirmou-se a natureza da leitura no contexto digital como uma prática socialmente situada, conforme postulado por Street (1984) e Bloome (1992), em oposição à perspectiva da leitura como algo que se que faz solitariamente com o texto. Conforme complementam outros autores, a maneira como um texto, digital ou não, é lido, é mediada pelo que os outros esperam que seja dito e feito com o texto, pois "a leitura é um processo social mesmo quando alguém a faz sozinho em outro espaço" (CASTANHEIRA, GREEN, DIXON, 2007, p. 25). Nesse caso, ao compartilhar, curtir ou postar, os usuários do telecentro respondiam às normas e expectativas de como ler textos e interagir com outros participantes em redes sociais no espaço digital. 
Passaremos agora a caracterizar a leitura conforme realizada durante a modalidade de uso orientado dos computadores durante o curso de inclusão digital. O material utilizado nesse curso foi adaptado de um outro material elaborado pelo coordenador de documentação do projeto LibreOffice $e^{5}$ intitulado "Introdução à informática com software livre".

Os textos e as atividades propostas visavam o conhecimento e o exercício dos procedimentos a serem executados no uso de diferentes softwares, hardware, software livre e conhecimentos sobre processadores de textos, planilhas de cálculo, gráficos, introdução à internet, navegadores de internet, e-mail, redes sociais e mensageiro instantâneo. As atividades do curso estavam também voltadas para a aquisição de habilidades para processamento de textos que constavam no material impresso, tendo como objetivo o domínio dos códigos que permitiam utilizar seus comandos para práticas efetivas de digitação de texto, como conhecer o teclado e aprender a lidar com as ferramentas para escrever um texto, ou seja, informações que o usuário precisa aprender a codificar e decodificar.

A análise de eventos de leitura ocorridos durante as aulas de inclusão digital evidenciou que as instrutoras sempre utilizavam como material didático as atividades propostas no material impresso. As informações gerais sobre determinado programa eram seguidas pela proposição de exercícios que deviam ser realizados pelos alunos no computador. No caso do processador para edição de texto, por exemplo, esses exercícios envolviam a identificação de informações objetivas no texto introdutório ou aspectos como formatação de fonte, texto, cor, inserção de formas, tabelas, desenhos, cores de fundo, entre outros aspectos para a aquisição de habilidades de digitação no computador (Figura 1).

${ }^{5}$ O LibreOffice é uma suíte de aplicativos de código aberto que apresenta como componentes o processador de textos Writer, a planilha Calc, o editor de apresentações Impress, a aplicação de desenho e fluxogramas Draw, o banco de dados Base e o editor de equações Math. 
Figura 1 - Atividades do material do curso de inclusão digital
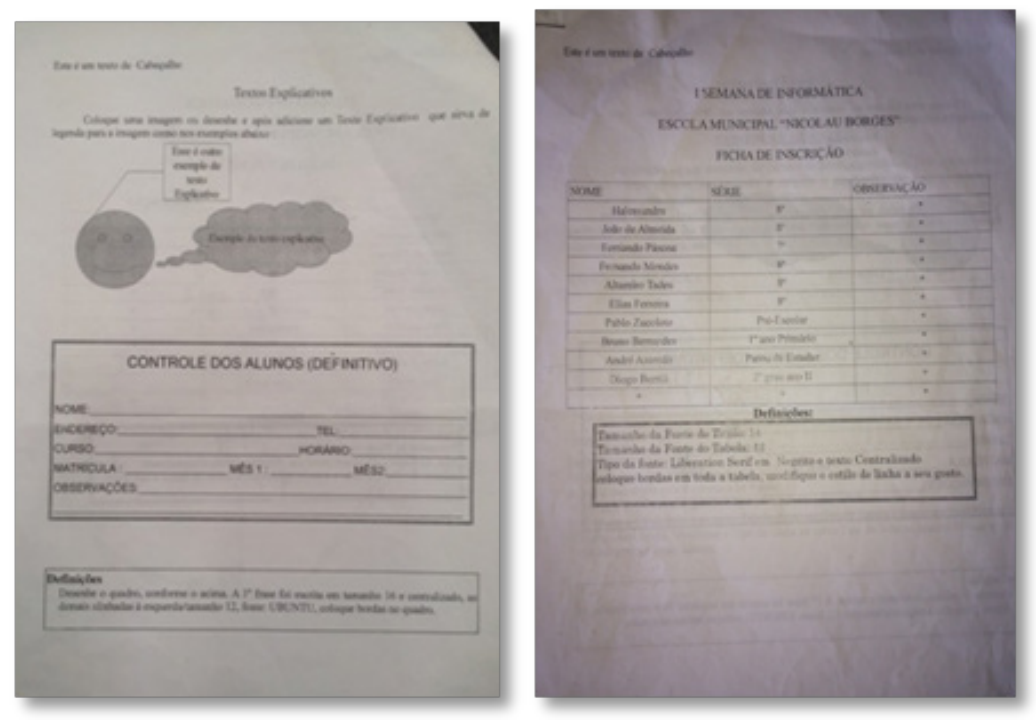

Fonte: Acervo das pesquisadoras.

A leitura desenvolvida na modalidade de uso orientado do computador privilegiou o reconhecimento dos ícones e outras unidades de significação que compõem os aplicativos do LibreOffice. As atividades buscavam levar, por exemplo, ao reconhecimento de ícones da tela do processador de textos Write, a manusear o mouse para percorrer o cursor pela tela e clicar nos ícones de formatação desejados, ou seja, operar com um conjunto de recursos semióticos para a elaboração das atividades. Assim, as informações sobre determinado aplicativo eram apresentadas como etapas mecânicas a serem seguidas ou por meio da apresentação de elementos discretos de um aplicativo para o qual não se propunha um uso efetivo (por exemplo, usar o processador de textos para editar textos produzidos pelos participantes da turma). Pode-se dizer, então, que essas atividades eram realizadas de forma descontextualizada, sendo um fim em si mesmas, sem envolver destinatários potenciais, exceto as monitoras que 
se preocupavam em cumprir um calendário determinado pelos coordenadores do IFNMG.

Durante atividades na modalidade de uso orientado dos computadores, o aluno podia engajar-se ou não nas atividades propostas pelas monitoras. Por exemplo, certo dia, uma aluna reclamou da atividade sobre textos explicativos (Figura 1) do curso de inclusão digital; fechou a tela da atividade e acessou o Facebook, movimento que foi acompanhado pelos colegas, não tendo sido observada nenhuma repreensão ou reprovação por parte das instrutoras. Notou-se com isso que a atividade de leitura para formatação de textos, como outras propostas durante as aulas do curso, se mostrou pouco interessante para os alunos. Por vezes, os alunos ficavam mais tempo utilizando livremente os computadores e, somente ao final da aula realizavam as atividades do curso de inclusão digital, sem, contudo, se sentirem pressionados para realização das atividades. Tal aspecto leva a crer que essa falta de interesse por parte dos alunos estaria relacionada à utilização do teclado sem um fim pragmático ou social como, por exemplo, para realizar pesquisas ou se comunicar com outras pessoas como faziam quando podiam usar os computadores livremente. Dessa forma, as habilidades a serem adquiridas por meio de exercícios de digitação pareciam desvinculadas do contexto local.

\section{Considerações finais}

A análise de eventos de leitura desenvolvidos pelos alunos do curso de inclusão digital do telecentro Maria Rocha, a partir de uma abordagem social do letramento, evidenciou que esses eventos estavam vinculados a duas modalidades de uso dos computadores e de acesso à internet: a modalidade de uso livre e a modalidade de uso orientado.

Foi possível observar que, na modalidade de uso livre do computador e da internet, os usuários definiam os percursos de leitura de acordo com seus interesses, demonstrando conhecimento e domínio de uso de ícones, mecanismos de busca, rotas de navegação e formas de estabelecer comunicação com outros participantes de redes sociais, entre 
outros aspectos. Não podemos traçar a gênese desse domínio, posto que ao terem acesso ao telecentro, seus usuários já demonstravam tais conhecimentos e habilidades.

Demonstramos como essas práticas de leitura estavam vinculadas não só ao contexto local, mas também a contextos sociais distantes, por exemplo, pela troca de mensagens, fotos ou vídeos com familiares e amigos que se encontravam em outras localidades. A importância dessa possiblidade de interação para os usuários do centro deve ser considerada à luz de movimentos migratórios por parte de familiares e amigos que vão em busca de trabalho em outras localidades. Além disso, a leitura de textos em gêneros diversos produzidos por autores vinculados a instituições distantes (por exemplo universidades, clubes de futebol, redes de televisão, produtos de beleza) também deve ser reconhecida como vinculações entre o contexto local e a outros contextos sociais mais distantes. Ademais, não se pode perder de vista que as novas tecnologias (seja o maquinário, sejam os diversos aplicativos) foram produzidos com características, propiciamentos e fins originados em outros contextos institucionais e sociais. Na modalidade de uso livre, as práticas de leitura estavam mais diretamente vinculadas à participação dos usuários do telecentro nas redes sociais, às interações com os amigos e à realização de tarefas escolares ou pesquisas sobre temas de interesse pessoal. Os diferentes usos do computador fomentam várias práticas de leitura que, muitas vezes, são ignoradas ou não reconhecidas pelas instituições escolares ou gestores de políticas públicas para a inclusão digital.

A análise de eventos de leitura ocorridos durante o curso para inclusão digital (modalidade de uso orientado dos computadores) demonstrou que as atividades propostas não se mostraram consonantes com os interesses dos usuários do telecentro. Essas atividades não estavam articuladas às funções e usos da escrita buscados por esses participantes. As análises mostram que, em relação à construção dos materiais didáticos para o curso, não foram consideradas a natureza das escolhas, experiências e conhecimentos dos alunos sobre o que, como e quando acessar e utilizar vários sites encontrados na rede. Nesse sentido, nota-se uma desconsideração dos conhecimentos locais pelos gestores de políticas públicas 
para inclusão digital, estas que objetivam o atendimento das demandas específicas dos grupos sociais. Como consequência disso, é possível supor que a resistência a realizar algumas atividades do curso ou a falta de interesse decorreram da falta de relevância das atividades propostas para os alunos, levando à limitação das possibilidades de aprendizagem do que se buscava ensinar. Assim, as práticas de leitura desenvolvidas nessa modalidade apresentam predominantemente características de um modelo autônomo do letramento, marcado por uma visão do conhecimento e do uso de softwares como algo simplesmente técnico, que uma vez aprendido, poderia ser utilizado automaticamente em outros contextos.

Pode-se concluir que a proposta do curso, uma ação educacional do programa de inclusão digital, privilegiou instruções relacionadas aos equipamentos e aos softwares básicos para uso da máquina, desconsiderando dimensões sociais e culturais vivenciadas pelos alunos em outros espaços sociais. Dessa forma, os alunos mostraram-se desmotivados e pouco se engajaram exploração e aprendizagem do que estava sendo ensinado. A análise apresentada sugere que as reivindicações, necessidades, conhecimentos e interesses da população a serem atendidas não foram, de fato, levadas em conta para planejamento de cursos que visam promover a inclusão digital. Finalizando, argumentamos que para a modificação desse quadro é necessário continuar investigando o que significa ser incluído digitalmente do ponto de vista da população a ser atendida por tais políticas, e que se leve em conta seus interesses e conhecimentos prévios como ponto de partida para o planejamento. Afinal, o conhecimento das práticas locais de letramento digital pode favorecer o atendimento dos reais interesses das pessoas para as quais essas políticas são endereçadas.

\section{Referências}

BATISTA, A. A. G. Práticas de leitura. Glossário do Ceale. Belo Horizonte: UFMG/ Faculdade de Educação, 2014. Disponível em: <http://www.ceale.fae.ufmg.br/ app/webroot/glossarioceale/>. Acesso em: 24 jul. 2018. 
BLOOME, D. Reading as a Social Process. Advances in Reading Language Research, v. 4, 1992.

BLOOME, D; EGAN-ROBERTSON, A. The social construction of intertextuality and classroom reading and writing. Reading Research Quartely, v. 28, n. 4, p. 304333, 1993.

BRASIL, Ministério das Comunicações. 2010. Disponível em https://www.mctic. gov.br/mctic/opencms/comunicacao/SETEL/inclusao_digital/telecentros/ TELECENTROS.html . Acesso em: 24/06/2018.

CASTANHEIRA, M. L; GREEN, J. L.;DIXON, C. N. Práticas de letramento em sala de aula: uma análise de ações letradas como construção social. Revista Portuguesa de Educação. CIEd - Universidade do Minho, 2007.

GREEN, J.; BLOOME, D. Etnography and etnographers of and in education: A situated perspective. In: FLOOD, J.; HEATH, S. B.; LAPP, D. (Eds.) Handbook of research on teaching literacy through the communicative and visual arts. New York: MacmillianPublish, 1997. p. 181-202.

HEATH, S. B. Ways With Words. Cambridge: CUP, 1983.

HEATH, S; STREET, B. Onethnography: approaches to language and literacy research. New York: Teachers College Press, 2008.

LANKSHEAR, C.; SNYDER, I.; GREEN, B. Teachers and technoliteracy: Managing literacy, technology and learning in schools. Sydney: Allen \&Unwin, 2000.

LANKSHEAR, C.; KNOBEL, M. Digital literacy and digital Literacies: policy, pedagogy and research considerations for education. Digital Kompetanse, v. 1, p. 12-24, 2006.

SANTAELLA, L. Navegar no Ciberespaço: o perfil cognitivo do leitor imersivo São Paulo: Paulus, 2004.

STREET, B. V. Literacy in Theory and Practice. Cambridge: CUP, 1984. 
STREET, B. "What's "new" in New Literacy Studies? Critical approaches to literacy in theory and practice", Current Issues in Comparative Education, v. 5, n. 2, 2003. p.77-91.

STREET, B. V. Letramentos sociais: abordagens críticas do letramento no desenvolvimento da etnografia e na educação. São Paulo: Parábola editorial, 2014.

STREeT, B; CASTANHEIRA, M. L. Práticas e eventos de letramento. Glossário do Ceale. Belo Horizonte, UFMG/Faculdade de Educação, 2014.

VELLOSO, M. J. M. Práticas de letramento no contexto digital: usos da leitura e da escrita no telecentro de uma comunidade quilombola. $235 \mathrm{f}$. Tese (Doutorado em Educação) — Faculdade de Educação, UFMG, Belo horizonte, 2015.

ZENHA, L.; CORDEIRO, L. Z. Produção em rede de materiais didáticos online para formação de jovens monitores do Programa telecentros. Anais do SIED: EnPED-ISSN 2316-8722, v. 1, n. 1, 2012.

Recebido: 31/07/2018

Received: 07/31/2018

Aprovado: 07/02/2019 Approved: 02/07/2019 